\title{
KRAS mutation analysis in ovarian samples using a high sensitivity biochip assay \\ Veronika Auner* ${ }^{* 1,2}$, Gernot Kriegshäuser ${ }^{\dagger 2}$, Dan Tong1, Reinhard Horvat ${ }^{3}$, Alexander Reinthaller ${ }^{1}$, Alexander Mustea ${ }^{4}$ and Robert Zeillinger ${ }^{1,2}$
}

\begin{abstract}
Address: ${ }^{1}$ Division of Gynaecology, Department of Obstetrics and Gynaecology, Medical University of Vienna, Vienna, Austria, ${ }^{2}$ ViennaLab Diagnostics GmbH, Vienna, Austria, ${ }^{3}$ Department of Clinical Pathology, Medical University of Vienna, Vienna, Austria and ${ }^{4}$ Department of Obstetrics and Gynaecology, Charité Medical University Berlin Campus Virchow-Klinikum, D-13353 Berlin, Germany

Email: Veronika Auner* - veronika.auner@meduniwien.ac.at; Gernot Kriegshäuser - kriegshauser@viennalab.co.at; Dan Tong - dan.cacsirecastillo@meduniwien.ac.at; Reinhard Horvat - reinhard.horvat@meduniwien.ac.at; Alexander Reinthaller - alexander.reinthaller@meduniwien.ac.at; Alexander Mustea - alexander.mustea@uni-greifswald.de; Robert Zeillinger - robert.zeillinger@meduniwien.ac.at

* Corresponding author †Equal contributors
\end{abstract}

Published: 9 April 2009

BMC Cancer 2009, 9: I I I doi:10.1 |86/|47|-2407-9-III
Received: 2 December 2008

Accepted: 9 April 2009

This article is available from: http://www.biomedcentral.com/I47I-2407/9/III

(C) 2009 Auner et al; licensee BioMed Central Ltd.

This is an Open Access article distributed under the terms of the Creative Commons Attribution License (http://creativecommons.org/licenses/by/2.0), which permits unrestricted use, distribution, and reproduction in any medium, provided the original work is properly cited.

\begin{abstract}
Background: Mutations in the KRAS gene are one of the most frequent genetic abnormalities in ovarian carcinoma. They are of renewed interest as new epidermal growth factor receptor (EGFR)targeted therapies are being investigated for use in ovarian carcinoma. As KRAS mutations are associated with poor response and resistance to EGFR-targeting drugs, this study was conducted to obtain more information on the spectrum of KRAS mutations in ovarian carcinoma.
\end{abstract}

Methods: The presence of KRAS mutations in codon 12 and 13 was analyzed in frozen and formalin-fixed paraffin-embedded (FFPE) tissue with a low density biochip platform. 38 I malignant (29 borderline malignancy, 270 primary carcinomas, and 82 recurrent carcinomas) and 22 benign tissue samples from a total of 394 patients were examined. KRAS mutational status of each sample was correlated with dignity, FIGO stage, grade, histology, and survival.

Results: KRAS mutations were found in 60 (15\%) samples with 58 samples deriving from malignant tissue and 2 samples deriving from benign tissue. In 55 (92\%) samples codon 12 was found to be mutated. Frozen and FFPE samples concurred with respect to KRAS mutation status.

Conclusion: KRAS mutation is a common event in ovarian cancer primarily in carcinomas of lower grade, lower FIGO stage, and mucinous histotype. The KRAS mutational status is no prognostic factor for patients treated with standard therapy. However, in line with experience from colorectal cancer and non-small-cell-lung cancer (NSCLC), it may be important for prediction of response to EGFR-targeted therapies.

\section{Background}

According to WHO statistics reported in 2005, ovarian cancer was ranked 5 th in cancer related death in Europe.
As in other tumors, the triggers of ovarian cancer involve genetic alterations and mutations. The discovery of underlying mechanisms that lead to an adverse patient outcome is of great importance. 
One of the best known DNA alterations in a variety of cancers is the mutational activation of ras protein family members. In fact, $20-30 \%$ of all human tumors harbour a mutation in a member of the ras family [1]. In ovarian cancer, KRAS mutations belong to the most frequently observed abnormalities [2].

The ras proteins are small GTPases, downstream of EGFR, which normally cycle between their active and inactive state. In health, ras proteins are key components in many pathways that couple growth factor receptors to downstream mitogenic effectors involved in cell proliferation and differentiation.

The most common mutations of these genes are found in codons 12,13 and 61, which lead to a constitutively active ras protein, and subsequently to an inappropriate increase in proliferation and malignant transformation [1]. In ovarian cancer, mutations most often affect codons 12 and 13 of the KRAS gene, with mutation rates reported to be as high as 3$11 \%[3,4]$. Mutations in codon 61 are rare in ovarian cancer $[5,6]$, and therefore will not be considered in this study.

It is known that non-small-cell-lung cancer (NSCLC) and colorectal cancer (CRC) patients with mutant KRAS show poor response to anti-EGFR therapy [7-10]. Because ovarian cancer patients are also being considered for treatment with EGFR-targeting substances, and as clinical trials are already conducted, it is crucial to know whether patients harbouring a ras mutation may benefit from such therapy.

In this study, 403 malignant and benign samples from 394 patients were analyzed for the presence of mutations in the KRAS gene at codons 12 and 13 using a biochip array hybridization method called GeneStix [11]. To our knowledge, this is the largest number of ovarian cancer samples analyzed in this manner with the sample size being twice as large as in the studies of Sieben [12] and Gemignani [13].

\section{Methods \\ Patients}

403 samples from 394 patients were examined. 381 malignant tissue samples (borderline malignancies, primary and recurrent ovarian carcinomas) from 377 patients and 22 samples from benign tissue ( 6 ovarian tissues and 16 ovarian cystadenomas) derived from 21 patients were analyzed. More than one sample was available for a total of 9 patients; including primary and recurrent lesions for 3 patients, 2 distinct recurrent lesions for 1 patient, healthy tissue and primary lesions for 2 patients, healthy and borderline tissue for 1 patient, and cystadenoma and healthy tissue for 2 patients.

170 samples were obtained from patients treated at the Department of Obstetrics and Gynaecology, Charité University Hospital, Campus Virchow, Berlin. 233 samples were collected at the Department of Obstetrics and Gynaecology, Medical University Vienna, Vienna. Samples were collected between 1989 and 2006.

Tissue attained in Berlin was fresh frozen to $-80^{\circ} \mathrm{C}$, and samples from Vienna were either formalin-fixed paraffinembedded (FFPE) $(\mathrm{n}=110)$ or fresh frozen to $-80^{\circ} \mathrm{C}(\mathrm{n}=$ 123). Patients gave their written informed consent and the study was approved by the local institutional review boards.

\section{Preparation of Samples}

FFPE samples were punched out of tissue blocks (Tissue Microarrayer I; Beecher Instruments, Sun Prairie, USA) and the DNA was extracted according to Fabjani et al. [14].

Briefly, the samples were washed repeatedly with xylene and ethanol and thereafter dried. Each dried pellet was resuspended in $250 \mu \mathrm{L}$ of a solution containing $12.5 \mathrm{mg}$ glass beads (Glass Controlled Pore, 120-200 $\mu \mathrm{m}$ mesh; Sigma), PCR amplification-buffer, and Proteinase K (0.6 $\mathrm{mg} / \mathrm{mL}$ ). The samples were incubated in an ultrasonic water bath at $56^{\circ} \mathrm{C}$ for $30 \mathrm{~min}$ followed by incubation at $95^{\circ} \mathrm{C} 10 \mathrm{~min}$ in a conventional thermoblock (Eppendorf AG, Hamburg, Germany) to inactivate proteinase K. Subsequently, the samples were centrifuged and the DNA containing supernatant was used for further analysis.

DNA from frozen samples obtained in Vienna was isolated using a salt elution method. Briefly, up to $1 \mathrm{~g}$ tissue was pulverized with a microdismembrator. The powdered tissue was suspended in $3 \mathrm{~mL}$ lysis buffer $(2.34 \% \mathrm{NaCl}, 10 \mathrm{mM}$ Tris- $\mathrm{HCl}$ and $1 \mathrm{mM}$ EDTA, $\mathrm{pH}=8) .100 \mu \mathrm{L}$ solubilizer ( $20 \%$ sodium dodecyl sulfate solution) and $100 \mu \mathrm{L}$ of $2 \%$ proteinase K (Sigma-Aldrich, St. Louis, USA) solution were added. Lysis was performed by overnight incubation at $37^{\circ} \mathrm{C}$ with gentle agitation. After cooling the sample to room temperature (RT), $1.4 \mathrm{~mL}$ saturated salt solution was added. The mixture was centrifuged at $10000 \times \mathrm{g}$ for $15 \mathrm{~min}$ at RT and DNA was precipitated by adding 2 volumes of $100 \%$ ethanol and the supernatant removed. After air-drying for 5 minutes, DNA was dissolved in $200 \mu \mathrm{L}$ Tris-EDTA buffer (10 mM Tris-HCl, 1 mM EDTA, pH = 8).

The DNeasy Blood \& Tissue Kit (Qiagen, Hilden, Germany) was used to isolate DNA from samples collected in Berlin.

\section{Mutation Analysis}

The GeneStix biochip platform has been optimized for the simultaneous detection of 10 frequent mutations found in codons 12 and 13 of the KRAS gene [11].

The biochip consists of a plastic stick with DNA capture oligonucleotides immobilized at the tip, and the entirely 
contained in a cylindrical tube. Samples were analyzed by hybridization to the biochip array after mutant-enriched PCR as described by Fabjani et al. [15].

In summary, downstream primers were biotin-labeled, upstream primers were phosphorylated at the 5 ' position. $20 \mu \mathrm{L}$ of the PCR products were digested with $1 \mu \mathrm{L} \lambda$-Exonuclease (New England BioLabs, Ipswich, USA) for 30 minutes at RT. In a GeneStix tube, $10 \mu \mathrm{L}$ of the digested PCR products were diluted in $200 \mu \mathrm{L}$ hybridization buffer including a hybridization control target. Stick hybridization was performed at $37^{\circ} \mathrm{C}$ for $1 \mathrm{~h}$ in a conventional thermoshaker (Eppendorf AG, Hamburg, Germany).

Without additional washing steps, the biochip was stained for $15 \mathrm{~min}$ with the provided streptavidin-horseradish peroxidase conjugate, and thereafter rinsed with 1 $\mathrm{mL}$ of assay buffer. The stick was then analyzed with the GeneStix-Imager, a chemiluminescence detector developed for use with the GeneStix system. Images were automatically processed with the test-specific analysis software provided with the imager.

Previously, the assay's limit for detecting KRAS mutations was determined using $0.1 \mathrm{ng}$ of tumor cell line DNA mixed with $100 \mathrm{ng}$ of wild-type DNA [11]. Even in this 1000-fold excess of wild-type DNA, GeneStix hybridization unambiguously identified all KRAS mutations covered by the assay. In the same study, 26 stool samples were analyzed in parallel by biochip hybridization and sequencing. Biochip-based hybridization detected KRAS mutations in $9 / 26$ (35\%) samples, all of which were confirmed by sequencing.

\section{Statistics}

To test for differences between groups, in regard to mutation rate, the Pearson's chi-square test was used. Tests included mutational rates of borderline lesions versus carcinoma, primary versus recurrent carcinoma, grade 1 mucinous tumors versus higher grade mucinous tumors, and the incidence of recurrence in primary carcinoma.

For deeper insight into factors consisting of more than two groups, such as overall and mucinous histotype grading (1-3), FIGO stage (I-III), and nodal status in carcinoma, and for histology (serous, mucinous, endometrioid, others/unknown) in all malignant samples, a residual analysis with adjusted standardized residuals was done.

To test for relation between patient age and the mutational rate, a Mann-Whitney-U test was performed.

For patients with primary ovarian cancer overall and recurrence free survival was calculated with univariate Log rank and Cox regression adjusted for FIGO. All statistical calculations were conducted with SPSS 15.0 (SPSS Inc; Chicago, IL, USA).

\section{Results}

\section{Basic results}

Of the 403 samples examined, 60 (15\%) contained mutations at codon 12 or 13 . The most frequent mutation was asp12 (40\%) followed by val12 (23\%) and cys12 (13\%). Overall, $92 \%$ of the mutations were located in codon 12 . Two patients carried double mutations (Table 1).

Overall, mutations were more common in borderline lesions $(35 \%)$ than in primary carcinoma $(16 \%)$ and recurrent ovarian carcinoma (6\%). Two of the 16 ovarian cystadenoma samples contained mutations, no mutation was found in healthy ovarian tissue.

Multiple samples were analyzed from 9 patients. A KRAS mutation was detected in only one of these. Of this patient, the primary and recurrent lesion could be analyzed and identical mutations were found in both lesions.

Mucinous lesions displayed mutations most frequently. The mutational rate increased from 50\% in mucinous borderline lesions to $60 \%$ in primary tumors of the same histotype (Tables 2 and 3). In serous lesions KRAS mutations occurred less frequently. Compared to mucinous lesions, serous malignancies exhibited a relatively high mutational frequency in borderline tumors $(35 \%)$ and fewer mutations in carcinoma (9\%) (Tables 2 and 3).

Table I: KRAS mutations examined samples

\begin{tabular}{|c|c|c|c|}
\hline mutation & amino acid & $\mathbf{n}$ & $\%$ \\
\hline $\mathrm{GGT} \rightarrow \mathrm{GAT}$ & gly $12 \rightarrow$ asp 12 & 24 & 40 \\
\hline $\mathrm{GGT} \rightarrow \mathrm{TGT}$ & gly $12 \rightarrow$ cys 12 & 8 & 13 \\
\hline $\mathrm{GGT} \rightarrow \mathrm{GTT}$ & gly $12 \rightarrow$ vall 2 & 14 & 23 \\
\hline $\mathrm{GGT} \rightarrow \mathrm{GCT}$ & gly $12 \rightarrow$ ala 12 & 4 & 7 \\
\hline $\mathrm{GGT} \rightarrow \mathrm{CGT}$ & gly $12 \rightarrow \arg 12$ & 2 & 3 \\
\hline $\mathrm{GGC} \rightarrow \mathrm{GAC}$ & glyl3 $\rightarrow$ aspl 3 & 4 & 7 \\
\hline $\mathrm{GGC} \rightarrow \mathrm{TGC}$ & glyl $3 \rightarrow$ cysl 3 & 1 & 2 \\
\hline GGT $\rightarrow$ GCT/GAT & gly $12 \rightarrow$ ala $12 /$ asp 12 & 2 & 3 \\
\hline \multirow[t]{2}{*}{ GGT $\rightarrow$ GTT/GAT } & gly $12 \rightarrow$ val $12 /$ asp 12 & 1 & 2 \\
\hline & total & 60 & 100 \\
\hline
\end{tabular}


Data from primary carcinoma was split up into FFPE and fresh frozen samples. Overall the percentage of mutation was very similar (14\% in FFPE tissue vs. $16 \%$ in fresh frozen tissue). Divided according to histotype the results were comparable. The only exception was seen in the mutational rate of mucinous tumors. This rate was much higher in FFPE samples. This is probably an artefact caused by the small sample size for this particular histotype (Table 4).

\section{Statistical results}

Pearson's chi-square test was used to compare mutation rates of borderline to cancerous lesions and primary to recurrent disease.

Borderline lesions more frequently contained mutations than tumors ( $\mathrm{p}=0.003)$, and the rate of mutation was significantly higher in primary tumors than recurrent tumors $(\mathrm{p}=0.023)$.

To get more insight into the relation between the mutation rate of carcinoma, nodal status, tumor grade (1-3), and FIGO classification (I-III) residual analysis was used.

Tumors with different grading showed a significant difference in mutation frequency.

Grade 1 tumors exhibited a significantly higher mutational rate than grade 3 tumors $(\mathrm{p}<0.0001)$. We found no significant difference in mutational rates in patients with different FIGO stages, but a trend towards a higher mutational rate could be seen in FIGO stage I tumors ( $\mathrm{p}=$ $0,081)$. No differences were found in rates of mutation related to nodal status.

When malignant samples were compared with respect to histology, the mutational rate in mucinous lesions was significantly higher than in lesions of other histotypes, whereas serous malignancies harboured significantly less KRAS mutations ( $\mathrm{p}<0.0001)$.

Table 2: KRAS mutation frequencies observed in borderline malignancies

\begin{tabular}{lccc}
\hline & \multicolumn{3}{l}{ borderline } \\
\cline { 2 - 4 } histotype & $\mathbf{n}$ & mutated & \% mutated \\
\hline serous & 20 & 7 & 35.00 \\
\hline endometroid & 1 & 0 & 0.00 \\
\hline mucinous & 6 & 3 & 50.00 \\
\hline unknown & 2 & 0 & 0.00 \\
\hline total & 29 & 10 & 34.48 \\
\hline
\end{tabular}

Because KRAS mutations are a typical feature of mucinous lesions, we studied the results of this subtype more closely. Similar to the statistical results independent of histotype, the mutation rates are significant higher in grade 1 carcinoma compared to higher grade mucinous tumors $(\mathrm{p}=0,007)$.

We also found, that tumors originating from younger patients more frequently contained a KRAS mutation (Mann-Whitney-U, p = 0.063). No statistical difference was found between the groups of patients with and without recurrence.

Furthermore, no significant difference could be found in recurrence free and overall survival, between patients with mutated and wildtype KRAS tumors. The log-rank test resulted in p-values of 0.258 for recurrence free, and 0.567 for overall survival respectively. FIGO corrected Cox regression showed p-values of 0.865 and 0.656 for recurrence free and overall survival.

\section{Discussion}

As of late KRAS mutations in ovarian cancer should stand in the center of attention again due to the availability of EGFR-targeted therapies (e.g. Gefitinib, Erlotinib, and Cetuximab), that are already in use to treat patients with NSCLC and metastatic CRC. These therapies are under discussion for treatment of ovarian cancer and numerous clinical trials are already in progress [16], however, not all patients respond equally to this treatment. In patients with NSCLC and CRC mutations in EGFR lead to a better prognosis under this medication [17-19], others show marginal if any response. Recently, KRAS activational mutations have been associated with a lack of sensitivity to anti-EGFR substances by maintaining the ability to continue aberrant signalling through the EGFR pathway, circumventing the blocked EGFR [7-10].

It has been shown that EGFR mutations do not play a role in ovarian cancer [20], while KRAS mutations are very well documented $[3,4,6,21]$.

The frequency of KRAS mutations was similar in frozen and FFPE tissue, indicating that our method is suitable for KRAS analysis in both types of tissue.

The mutation frequency found in borderline malignancies (34\%) and carcinomas (13\%), is well in line with previous reports $[3-5,22]$. Not surprisingly, benign ovarian tissue contained a minimal number of mutations.

Overall, the mutation rate in mucinous malignancies is much higher than in lesions of any other histological subtype. It is likely that KRAS mutation is associated with mucinous differentiation [23] as these mutations also accumulate in mucinous carcinomas obtained from other 
Table 3: KRAS mutation frequencies observed in carcinoma

\begin{tabular}{|c|c|c|c|c|c|c|c|c|c|}
\hline & \multicolumn{3}{|c|}{ primary carcinoma } & \multicolumn{3}{|c|}{ recurrent carcinoma } & \multicolumn{2}{|c|}{ carcinoma total } & \multirow[b]{2}{*}{$\%$ mutated } \\
\hline & $\mathbf{n}$ & mutated & $\%$ mutated & $\mathbf{n}$ & mutated & $\%$ mutated & $\mathbf{n}$ & mutated & \\
\hline & 270 & 43 & 15.93 & 82 & 5 & 6.10 & 352 & 48 & 13.64 \\
\hline \multicolumn{10}{|l|}{ histotype } \\
\hline serous & 177 & 17 & 9.60 & 69 & 4 & 5.80 & 246 & 21 & 8.54 \\
\hline endometroid & 34 & 4 & 11.76 & 5 & 0 & 0.00 & 39 & 4 & 10.26 \\
\hline mucinous & 25 & 15 & 60.00 & 5 & I & 20.00 & 30 & 16 & 53.33 \\
\hline clear cell & 19 & 5 & 26.32 & 2 & 0 & 0.00 & 21 & 5 & 23.81 \\
\hline undifferent. & 10 & 0 & 0.00 & 1 & 0 & 0.00 & II & 0 & 0.00 \\
\hline unknown & 5 & 2 & 40.00 & & & & 5 & 2 & 40.00 \\
\hline \multicolumn{10}{|l|}{ age } \\
\hline$\leq 50$ & 72 & 16 & 22.22 & 31 & 4 & 12.90 & 103 & 20 & 19.42 \\
\hline$>50$ & 198 & 27 & 13.64 & 51 & 1 & 1.96 & 249 & 28 & 11.24 \\
\hline \multicolumn{10}{|l|}{ grading } \\
\hline I & 33 & 17 & 51.52 & 7 & 0 & 0.00 & 40 & 17 & 42.50 \\
\hline 2 & 90 & 14 & 15.56 & 27 & 4 & $|4.8|$ & 117 & 18 & 15.38 \\
\hline 3 & $|4|$ & 12 & 8.51 & 46 & 1 & 2.17 & 187 & 13 & 6.95 \\
\hline 4 & 1 & 0 & 0.00 & 0 & 0 & 0.00 & 1 & 0 & 0.00 \\
\hline unknown & 5 & 0 & 0.00 & 2 & 0 & 0.00 & 7 & 0 & 0.00 \\
\hline
\end{tabular}

\section{FIGO stage}

\begin{tabular}{lccccccccc}
\hline 1 & 65 & 17 & 26.15 & 9 & 0 & 0.00 & 74 & 17 & 22.97 \\
\hline 2 & 31 & 5 & 16.13 & 8 & 0 & 0.00 & 39 & 5 & 12.82 \\
\hline 3 & 145 & 17 & 11.72 & 48 & 4 & 8.33 & 193 & 21 & 10.88 \\
\hline 4 & 28 & 4 & 14.29 & 13 & 1 & 7.69 & 41 & 5 & 12.20 \\
\hline unknown & 1 & 0 & 0.00 & 4 & 0 & 0.00 & 5 & 0 & 0.00 \\
\hline
\end{tabular}


Table 3: KRAS mutation frequencies observed in carcinoma (Continued)

\begin{tabular}{lllllllllll}
\hline $\mathbf{p N}$ & & & & & & & & \\
\hline 0 & 104 & 17 & 16.35 & 19 & 0 & 0.00 & 123 & 17 & 13.82 \\
\hline 1 & 67 & 7 & 10.45 & 28 & 4 & 14.29 & 95 & 11 & 11.58 & 14.93 \\
\hline $\mathrm{x}$ & 99 & 19 & 19.19 & 35 & 1 & 2.86 & 134 & 20 & \\
\hline
\end{tabular}

organs [24]. In agreement with other studies, a lower mutation rate was found in mucinous borderline malignancies compared to carcinoma $[4,24]$.

In line with other studies, we also find a smaller percentage of samples harbouring a mutation in serous borderline tumors than in serous carcinoma. In serous lesions KRAS mutation seems to be a typical feature of borderline tumors and low grade carcinoma. On the other hand, KRAS mutation does not seem to play a major role in high grade serous carcinoma. Russel and McCluggage [25] and also Kurman and Shih [21] proposed a new theory that distinguishes between high grade and low grade serous carcinoma and tries to reconstruct the different steps of development in those entities. KRAS, BRAF and PTEN mutations seem to be a feature of tumors with low malignant potential, whereas high grade carcinoma, which account for $90 \%$ of all serous carcinoma, harbour TP53 mutations and genetic instability [21]. The results of our study may not supply a new foundation for this theory; however, it stands well in line with the established notion of two separate pathways for the development of high and low grade serous ovarian carcinoma.

When KRAS mutational status was analyzed irrespective of histotype, grade 1 tumors showed a significantly higher mutational rate than grade 3 tumors. This is probably due to the predominance of serous samples in the group of high grade tumors. An almost equal number of serous and mucinous lesions are present in the group of grade 1 tumors. The group of grade 2 tumors contain 5 times more, and the group of grade 3 tumors over 50 times more serous than mucinous lesions. As stated above, serous tumors seldom harbour a KRAS mutation. Even if a mutation occurs, it will appear more probable in serous lesions with low malignant potential which would even amplify the described effect.

The higher number of KRAS mutations in lower grade samples could also be an explanation for the higher mutational rate in younger patients. Various studies have shown that patients with lower grading seem to be of younger age than patients with high grading [21].

Mutant and wildtype primary carcinoma showed no significant difference regarding the incidence of recurrent disease $(\mathrm{p}=0.114)$. There is also no difference in recurrence free survival or overall survival. Therefore, KRAS mutation cannot be considered a prognostic factor for standard chemotherapy.

The percentage of analyzed recurrent tumors bearing a mutation was therefore surprisingly low. The imbalance may be explained by the relatively small sample size of recurrent carcinomas and may be lost in the large sample variation.

One of the patients for whom multiple samples were analyzed, showed a mutation in the KRAS gene. As this mutation was found in both the primary carcinoma and the recurrent lesion, the mutational event must have taken

Table 4: KRAS mutations in FFPE tissue and frozen tissue

\begin{tabular}{lcccccc}
\hline & \multicolumn{3}{c}{ FFPE tissue } & \multicolumn{3}{c}{ frozen tissue } \\
\cline { 2 - 7 } histotype & $\mathbf{n}$ & mutated & \% mutated & $\mathbf{n}$ & mutated & $\%$ mutated \\
\hline serous & 50 & 2 & 4,00 & 127 & 15 & 7 \\
\hline mucinous & 9 & 8 & 88,89 & 16 & 8 & 43,75 \\
\hline others & 29 & 3 & 10,34 & 39 & 20,51 \\
\hline total & 88 & 13 & 14,77 & 182 & 30 & 16,48 \\
\hline
\end{tabular}


place in the primary lesion previous to the processes that led to recurrent disease.

Diebold et al. report six cases where tissue was taken from two contralateral borderline tumor masses harbouring a KRAS mutation. In all cases the mutations were present in each of the paired tumors examined [26]. Ho et al. detected corresponding mutations in borderline malignancies and the adjacent cystadenoma epithelium [27]. Therefore it could be concluded that mutations of KRAS are an early event in development of low grade tumors.

Our finding of one paired mutated primary and recurrent tumor is hardly enough evidence, but supports earlier findings from other groups and further supports the notion that such mutations are an early event in the malignant process.

\section{Conclusion}

In summary, KRAS mutation is a common event in ovarian cancer and is more frequently present in carcinoma of lower grade, lower FIGO stage, and in lesions of mucinous histotype. Our results support earlier findings from other groups in a very large number of samples. KRAS mutation was not found to be of prognostic value for patients under standard therapy, but these mutations could emerge as an important factor for individually tailored anti-EGFR therapies.

\section{Competing interests}

The authors declare that they have no competing interests.

\section{Authors' contributions}

VA and GK contributed equally to this project. Both did the practical work, wrote the text and did statistical analysis. RH was in charge of the analysis of the histological data from Viennese samples AR selected and provided clinical samples from Vienna, AM was responsible for acquisition and selection of the clinical samples from Berlin. RZ and DT designed and supervised the project and emended the manuscript. All authors read and approved the final manuscript.

\section{Acknowledgements}

Robert Eifler helped drafting and copyediting the manuscript, his source of funding is the Danube University Krems, Austria.

Source of funding of the study is the Medical University of Vienna. DT, RH, $A R$, and ZR are employees of the Medical University of Vienna. VA was employed by the Medical University of Vienna and Viennalab. GK is an employee of Viennalab, and AM is employed at Charité Medical University Berlin. The source of funding of the manuscript was the Medical University of Vienna. The funding bodies had no influence on the study design, the collection, analysis and interpretation of the data, writing and submission of the manuscript.

\section{References}

I. Bos JL: ras oncogenes in human cancer: a review. Cancer Res 1989, 49( I 7):4682-4689.

2. Nakayama N, Nakayama K, Yeasmin S, Ishibashi M, Katagiri A, lida K, Fukumoto $M$, Miyazaki $\mathrm{K}$ : KRAS or BRAF mutation status is a useful predictor of sensitivity to MEK inhibition in ovarian cancer. Br J Cancer 2008, 99( I 2):2020-2028.

3. Mayr D, Hirschmann A, Lohrs U, Diebold J: KRAS and BRAF mutations in ovarian tumors: a comprehensive study of invasive carcinomas, borderline tumors and extraovarian implants. Gynecol Oncol 2006, I 03(3):883-887.

4. Caduff RF, Svoboda-Newman SM, Ferguson AW, Johnston CM, Frank TS: Comparison of mutations of Ki-RAS and p53 immunoreactivity in borderline and malignant epithelial ovarian tumors. Am J Surg Pathol I999, 23(3):323-328.

5. Enomoto T, Weghorst CM, Inoue M, Tanizawa O, Rice JM: K-ras activation occurs frequently in mucinous adenocarcinomas and rarely in other common epithelial tumors of the human ovary. Am J Pathol 1991, I39(4):777-785.

6. Teneriello MG, Ebina M, Linnoila RI, Henry M, Nash JD, Park RC, Birrer MJ: p53 and Ki-ras gene mutations in epithelial ovarian neoplasms. Cancer Res 1993, 53(13):3103-3108.

7. Lievre A, Bachet JB, Boige V, Cayre A, Le Corre D, Buc E, Ychou M, Bouche $O$, Landi B, Louvet $C$, et al.: KRAS mutations as an independent prognostic factor in patients with advanced colorectal cancer treated with cetuximab. J Clin Oncol 2008, 26(3):374-379.

8. Khambata-Ford S, Garrett CR, Meropol NJ, Basik M, Harbison CT, Wu S, Wong TW, Huang $\mathrm{X}$, Takimoto $\mathrm{CH}$, Godwin AK, et al.: Expression of epiregulin and amphiregulin and K-ras mutation status predict disease control in metastatic colorectal cancer patients treated with cetuximab. J Clin Oncol 2007, 25(22):3230-3237.

9. Eberhard DA, Johnson BE, Amler LC, Goddard AD, Heldens SL, Herbst RS, Ince WL, Janne PA, Januario T, Johnson DH, et al.: Mutations in the epidermal growth factor receptor and in KRAS are predictive and prognostic indicators in patients with nonsmall-cell lung cancer treated with chemotherapy alone and in combination with erlotinib. J Clin Oncol 2005, 23(25):5900-5909.

10. van Zandwijk N, Mathy A, Boerrigter L, Ruijter H, Tielen I, de Jong D, Baas P, Burgers S, Nederlof P: EGFR and KRAS mutations as criteria for treatment with tyrosine kinase inhibitors: retroand prospective observations in non-small-cell lung cancer. Ann Oncol 2007, I 8(1):99-103.

I I. Prix L, Uciechowski P, Bockmann B, Giesing M, Schuetz AJ: Diagnostic biochip array for fast and sensitive detection of K-ras mutations in stool. Clin Chem 2002, 48(3):428-435.

12. Sieben NL, Macropoulos P, Roemen GM, Kolkman-Uljee SM, Jan Fleuren G, Houmadi R, Diss T, Warren B, Al Adnani M, De Goeij AP, et al.: In ovarian neoplasms, BRAF, but not KRAS, mutations are restricted to low-grade serous tumours. J Pathol 2004, 202(3):336-340.

13. Gemignani ML, Schlaerth AC, Bogomolniy F, Barakat RR, Lin O, Soslow R, Venkatraman E, Boyd J: Role of KRAS and BRAF gene mutations in mucinous ovarian carcinoma. Gynecol Oncol 2003, 90(2):378-381.

14. Fabjani G, Kucera E, Schuster E, Minai-Pour M, Czerwenka K, Sliutz $\mathrm{G}$, Leodolter S, Reiner A, Zeillinger R: Genetic alterations in endometrial hyperplasia and cancer. Cancer Lett 2002, I 75(2):205-2I I.

15. Fabjani G, Kriegshaeuser G, Schuetz A, Prix L, Zeillinger R: Biochip for K-ras mutation screening in ovarian cancer. Clin Chem 2005, 5 I (4):784-787.

16. Palayekar MJ, Herzog TJ: The emerging role of epidermal growth factor receptor inhibitors in ovarian cancer. Int J Gynecol Cancer 2008, I 8(5):879-890.

17. Zhu CQ, da Cunha Santos G, Ding K, Sakurada A, Cutz JC, Liu N, Zhang T, Marrano P, Whitehead M, Squire JA, et al.: Role of KRAS and EGFR as biomarkers of response to erlotinib in National Cancer Institute of Canada Clinical Trials Group Study BR.2 I. J Clin Oncol 2008, 26(26):4268-4275.

18. Endo K, Sasaki H, Yano M, Kobayashi Y, Yukiue H, Haneda H, Suzuki $\mathrm{E}$, Kawano O, Fujii $Y$ : Evaluation of the epidermal growth factor receptor gene mutation and copy number in non-small cell 
lung cancer with gefitinib therapy. Oncol Rep 2006, 16(3):533-54I.

19. Karapetis CS, Khambata-Ford S, Jonker DJ, O'Callaghan CJ, Tu D, Tebbutt NC, Simes RJ, Chalchal H, Shapiro JD, Robitaille S, et al.: Kras mutations and benefit from cetuximab in advanced colorectal cancer. N Engl J Med 2008, 359( I7): 1757- 1765.

20. Mustea A, Sehouli J, Fabjani G, Koensgen D, Mobus V, Braicu El, Pirvulescu C, Thomas A, Tong D, Zeillinger R: Epidermal growth factor receptor (EGFR) mutation does not correlate with platinum resistance in ovarian carcinoma. Results of a prospective pilot study. Anticancer Res 2007, 27(3B): I527-1530.

21. Kurman RJ, Shih le M: Pathogenesis of ovarian cancer: lessons from morphology and molecular biology and their clinical implications. Int J Gynecol Pathol 2008, 27(2): I5I-160.

22. Schuyer M, Henzen-Logmans SC, Burg ME van der, Fieret JH, Derksen C, Look MP, Meijer-van Gelder ME, Klijn JG, Foekens JA, Berns EM: Genetic alterations in ovarian borderline tumours and ovarian carcinomas. Eur J Obstet Gynecol Reprod Biol 1999, 82(2): $147-150$.

23. Fujita $M$, Enomoto $T$, Murata $Y$ : Genetic alterations in ovarian carcinoma: with specific reference to histological subtypes. Mol Cell Endocrinol 2003, 202(I-2):97-99.

24. Cuatrecasas M, Villanueva A, Matias-Guiu X, Prat J: K-ras mutations in mucinous ovarian tumors: a clinicopathologic and molecular study of 95 cases. Cancer 1997, 79(8): I58I- I586.

25. Russell SE, McCluggage WG: A multistep model for ovarian tumorigenesis: the value of mutation analysis in the KRAS and BRAF genes. J Pathol 2004, 203(2):6|7-619.

26. Diebold J, Seemuller F, Lohrs U: K-RAS mutations in ovarian and extraovarian lesions of serous tumors of borderline malignancy. Lab lnvest 2003, 83(2):25I-258.

27. Ho CL, Kurman RJ, Dehari R, Wang TL, Shih le M: Mutations of BRAF and KRAS precede the development of ovarian serous borderline tumors. Cancer Res 2004, 64(19):69|5-69|8.

\section{Pre-publication history}

The pre-publication history for this paper can be accessed here:

http://www.biomedcentral.com/1471-2407/9/111/pre

pub

Publish with Bio Med Central and every scientist can read your work free of charge

"BioMed Central will be the most significant development for disseminating the results of biomedical research in our lifetime. "

Sir Paul Nurse, Cancer Research UK

Your research papers will be:

- available free of charge to the entire biomedical community

- peer reviewed and published immediately upon acceptance

- cited in PubMed and archived on PubMed Central

- yours - you keep the copyright
BioMedcentral 